\title{
Digestibilidade aparente de ingredientes do Semi-Árido Nordestino para tilápia do Nilo
}

\author{
Apparent digestibility of ingredients of the Northeast Semi-Arid for Nile tilapia
}

\author{
Josivânia Rodrigues de Araújo ${ }^{\mathrm{I} *}$ Lilian Dena dos Santos ${ }^{\mathrm{II}}$ \\ Lilian Carolina Rosa da Silva ${ }^{\text {II }}$ Otanael Oliveira dos Santos ${ }^{\mathrm{I}}$ Fabio Meurer ${ }^{\mathrm{II}}$
}

\begin{abstract}
- NOTA-
RESUMO

O experimento avaliou o coeficiente de digestibilidade aparente (CDA) da matéria seca (MS), energia bruta (EB), extrato etéreo (EE) e proteína bruta $(P B)$ de ingredientes do Semi-Árido Nordestino: farinhas do feno de maniçoba (FM), do feno de leucena (FL) e do feno da folha de

$23.04 \%, 4.43 \%$ and $21.07 \%$ for $F F M, 72.85 \%, 70.62 \%$, $81.78 \%$ and $84.51 \%$ for $R M$ and $33.38 \%, 50.80 \%, 79.39 \%$ and $67.25 \%$ for RV. The leucaena hay, the cassava scrapings and residues of wine are promising for the formulation of diets for Nile tilapia. However, the use of tested ingredients in commercial and homemade diets to Nile tilapia, as well as the safe inclusion levels of these should be tested.
\end{abstract} mandioca (FFM), raspa de mandioca (RM) e resíduos de vitivinícola (RV) para tilápia do Nilo (Oreochromis niloticus). Os CDA para a MS, EB, EE e PB foram de 20,74\%, 30,30\%, $48,36 \%$ e $71,72 \%$ para $F L ; 19,34 \%, 17,08 \%, 30,03 \%$ e $44,88 \%$ para $F M ; 30,32 \%, 23,04 \%, 4,43 \%$ e $21,07 \%$ para FFM; 72,85\%, 70,62\%,81,78\% e 84,51\% para $R M$ e de $33,38 \%, 50,80 \%, 79,39 \%$ e $67,25 \%$ para $R V$. O feno de leucena, a raspa de mandioca e os resíduos de vitivinícola são promissores para a formulação de rações. A utilização dos ingredientes testados na composição de rações artesanais ou comercias para a tilápia do Nilo, bem como os níveis seguros para a inclusão destes devem ser testados.

Palavras-chave: alimento alternativo, cultivo de tilápia, nutrição de peixes, piscicultura.

\section{ABSTRACT}

The experiment evaluated the apparent digestibility coefficient (CDA) of dry matter (DM), gross energy (GE), ether extract (EE) and crude protein (CP) of regional alternative ingredients of Semi-arid Northeast as flour of maniçoba hay (FM), of Leucaena hay (FL) and of cassava leaves (FFM), as well as cassava scrapings (RM) and residues of wine (RV) for Nile tilapia (Oreochromis niloticus). CDA for DM, GE, EE and CP were $20.74 \%, 30.30 \%, 48.36 \%$ and $71.72 \%$ for $F L$, $19.34 \%, 17.08 \%, 30.03 \%$ and $44.88 \%$ for $F M, 30.32 \%$,
Key words: alternative feed, culture tilapia, fish nutrition, fish farming.

Dentre os ingredientes regionais do SemiÁrido Nordestino, destacam-se a Leucena, a maniçoba, folha de mandioca, a raspa de mandioca e os resíduos de vitivinícola. Dessa forma, a determinação dos valores dos nutrientes e energia digestíveis destes ingredientes, para a tilápia do Nilo, é importante para a sua utilização correta na composição de rações.

O presente trabalho objetivou determinar os coeficientes de digestibilidade aparente (CDA) da proteína bruta $(\mathrm{PB})$, energia bruta $(\mathrm{EB})$, matéria seca (MS) e extrato etéreo (EE) das farinhas de feno de maniçoba, leucena e folha de mandioca, bem como a raspa de mandioca e os resíduos de vitivinícola para tilápias do Nilo. O experimento foi conduzido no Campus de Ciências Agrárias da Universidade Federal do Vale do São Francisco (UNIVASF). O método utilizado para a avaliação do CDA foi o indireto de coleta de

'Programa de Pós-graduação em Ciência Animal, Universidade Federal do Vale do São Francisco (UNIVASF), Campus Ciências Agrárias, Rod BR 407, Km 12, Lote 543, Projeto de Irrigação Senador Nilo Coelho, S/N, C1, 56300-000, Petrolina, PE, Brasil. E-mail: josivaniaraujo@yahoo.com.br.*Autor para correspondência.

"Programa de Pós-graduação em Aquicultura e Desenvolvimento Sustentátel, Curso de Tecnologia em Aquicultura, Universidade Federal do Paraná (UFPR), Palotina, PR, Brasil. 
fezes utilizando $0,1 \mathrm{~g}$ de óxido crômico $\left(\mathrm{Cr}_{2} \mathrm{O}_{3}\right)$ como indicador inerte (MEURER et al., 2003).

O FL, RM e o RV eram provenientes da Embrapa Semi-Árido, Petrolina/PE. O FM foi obtido junto ao IF Sertão Pernambucano em Petrolina/PE. O FFM foi conseguido junto ao Campus de Ciências Agrárias da UNIVASF, em Petrolina/PE. As rações experimentais foram fabricadas conforme MEURER et al. (2011).

Foram utilizados 300 juvenis de tilápia do

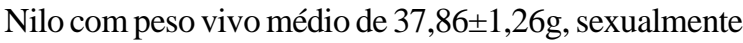
revertidos. Os peixes foram distribuídos em seis tanques rede circulares de tela plástica (malha de $1,50 \mathrm{~cm}$ ) com capacidade de $100 \mathrm{~L}$, contidos em seis tanques de alimentação de fibra de vidro de 1.000L e seis cubas de fibra de vidro cilíndricas de fundo cônico de 180L, adaptada a um recipiente para coleta de fezes por sedimentação. O manejo utilizado é semelhante ao descrito por MEURER et al. (2011).

As análises das fezes, rações e ingredientes, foram realizadas no Laboratório de Nutrição Animal da UNIVASF e da EMBRAPA Semi-Árido. A concentração do cromo foi determinada por espectrofotometria de absorção atômica e os cálculos dos CDA foram feitos de acordo MEURER et al. (2003).

Os valores da composição percentual bromatológica dos ingredientes testados para a tilápia do Nilo encontram-se na tabela 1 . Os valores dos CDA da MS, EB, PB e EE e os valores de PD, ED e EE dos ingredientes avaliados estão descritos na tabela 2.

O valor de CDA da MS do presente experimento para o FL foram inferiores ao apresentado por PEZZATO et al. (2004) para o FL, BIUDES et al. (2009) para o aguapé (Eichhornia crassipes), entretanto, semelhante ao sorgo (PEZZATO et al., 2002). Para o CDA da PB da FL, os resultados do presente estudo foram semelhantes aos de PEZZATO et al. (2004) para o FL, bem como à biomassa emersa do aguapé (BIUDES et al., 2009).

O CDA da EB da FL foi semelhante ao da biomassa submersa do aguapé (BIUDES et al., 2009) e ao farelo de coco (SANTOS et al., 2009) e inferior aos da levedura (MEURER et al., 2003) e da parte aérea do aguapé (BIUDES et al., 2009). O CDA do EE do FL foi superior ao do sorgo e inferior aos farelos de trigo e arroz (PEZZATO et al., 2002).

Os CDA para o FM tanto da MS, quanto da PB e EB foram inferiores aos do sorgo (PEZZATO et al., 2002), farelos de coco, resíduos de goiaba (SANTOS et al., 2009), levedura (MEURER et al., 2003), aguapé (BIUDES et al., 2009). O CDA da FFM, o CDA da MS é superior ao apresentado por PEZZATO et al. (2002) sendo que os demais valores de CDA para a PB e EB seguem o mesmo padrão apresentado para o FM.

O CDA da MS para a RM corrobora PEZZATO et al. (2004), bem como para o milho, sendo superior ao triticale e ao farelo de trigo, porém inferior à farinha de varredura de mandioca (BOSCOLO et al., 2002). O CDA da EB foi inferior aos ingredientes energéticos determinados por BOSCOLO et al. (2002). O valor de ED é semelhante aos determinados por PEZZATO et al. (2004) para o mesmo ingrediente e para o sorgo e superior aos valores encontrados para o amido de milho e milho extrusado (PEZZATO et al., 2002).

O CDA da MS para a RV foi superior ao sorgo e inferior aos demais ingredientes energéticos descritos por BOSCOLO et al. (2002). O CDA da EB do RV foi superior ao do farelo de coco (SANTOS et al., 2009) e inferior à levedura (MEURER et al., 2003). O CDA da PB foi superior aos valores do urucum, feno de alfafa e a farinha de algaroba (PEZZATO et al., 2004).

Tabela 1 - Composição percentual bromatológica das rações e ingredientes testados para a tilápia do Nilo, com base na matéria seca.

\begin{tabular}{|c|c|c|c|c|c|}
\hline Rações & $\mathrm{MS}^{1}$ & $\mathrm{MM}^{2}$ & $\mathrm{~PB}^{3}$ & $\mathrm{~EB}^{4}\left(\mathrm{kcal} \mathrm{kg}^{-1}\right)$ & $\mathrm{EE}^{5}$ \\
\hline $\mathrm{FL}^{6}$ & 93,62 & 8,05 & 30,94 & $4.400,97$ & 4,21 \\
\hline $\mathrm{FM}^{7}$ & 91,98 & 8,20 & 31,26 & $4.178,22$ & 5,31 \\
\hline FFM $^{8}$ & 93,25 & 8,01 & 30,15 & $4.493,13$ & 5,71 \\
\hline $\mathrm{RM}^{9}$ & 94,53 & 7,33 & 24,45 & $4.252,38$ & 2,39 \\
\hline $\mathrm{RV}^{10}$ & 94,57 & 7,14 & 27,20 & $4.783,25$ & 6,05 \\
\hline Ingredientes & $\mathrm{MS}^{1}$ & $\mathrm{MM}^{2}$ & $\mathrm{~PB}^{3}$ & $\mathrm{~EB}^{4}\left(\mathrm{kcal} \mathrm{kg}^{-1}\right)$ & $\mathrm{EE}^{5}$ \\
\hline $\mathrm{FL}^{6}$ & 91,97 & 8,43 & 28,26 & $4.856,89$ & 3,21 \\
\hline $\mathrm{FM}^{7}$ & 92,82 & 7,58 & 23,32 & $4.674,44$ & 3,83 \\
\hline FFM $^{8}$ & 91,98 & 7,46 & 18,92 & $4.824,90$ & 4,97 \\
\hline $\mathrm{RM}^{9}$ & 93,21 & 4,68 & 2,59 & $3.802,36$ & 1,25 \\
\hline $\mathrm{RV}^{10}$ & 95,33 & 5,16 & 9,37 & $4.883,42$ & 8,18 \\
\hline
\end{tabular}

${ }^{1}$ Matéria seca; ${ }^{2}$ Matéria mineral; ${ }^{3}$ Proteína bruta; ${ }^{4}$ Energia bruta; ${ }^{5}$ Extrato etéreo; ${ }^{6}$ Feno de leucena; ${ }^{7}$ Feno de maniçoba; ${ }^{8}$ Feno da folha de mandioca; ${ }^{9}$ Raspas de mandioca; ${ }^{10}$ Resíduos de vitivinícola. 
Tabela 2 - Coeficientes de digestibilidade aparente e valores digestíveis dos ingredientes testados nas dietas experimentais para tilápia do Nilo.

\begin{tabular}{|c|c|c|c|c|}
\hline \multirow[t]{2}{*}{ Ingredientes } & \multirow[b]{2}{*}{$\mathrm{MS}^{1}$} & \multirow[b]{2}{*}{$\mathrm{PB}^{2}$} & aparent & \multirow[b]{2}{*}{$\mathrm{EE}^{4}$} \\
\hline & & & $\mathrm{EB}^{3}$ & \\
\hline $\mathrm{FL}^{5}$ & 20,74 & 71,72 & 30,30 & 48,36 \\
\hline $\mathrm{FM}^{6}$ & 19,34 & 44,88 & 17,08 & 30,03 \\
\hline $\mathrm{FFM}^{7}$ & 30,32 & 21,07 & 23,04 & 4,43 \\
\hline $\mathrm{RM}^{8}$ & 72,85 & 84,51 & 70,62 & 81,78 \\
\hline \multirow[t]{2}{*}{$\mathrm{RV}^{9}$} & 33,38 & 67,25 & 50,80 & 79,39 \\
\hline & $\mathrm{PD}^{10}(\%)$ & \multicolumn{2}{|c|}{$\mathrm{ED}^{11}\left(\mathrm{kcal} \mathrm{kg}^{-1}\right)$} & $\mathrm{EE}^{4}(\%)$ \\
\hline $\mathrm{FL}^{5}$ & 20,34 & \multicolumn{2}{|c|}{971,38} & 1,54 \\
\hline $\mathrm{FM}^{6}$ & 10,49 & \multicolumn{2}{|c|}{794,54} & 1,15 \\
\hline $\mathrm{FFM}^{7}$ & 3,97 & \multicolumn{2}{|c|}{$1.109,72$} & 0,20 \\
\hline $\mathrm{RM}^{8}$ & 2,20 & \multicolumn{2}{|c|}{$2.699,67$} & 1,02 \\
\hline $\mathrm{RV}^{9}$ & 6,28 & \multicolumn{2}{|c|}{$2.490,54$} & 6,46 \\
\hline
\end{tabular}

${ }^{1}$ Matéria seca; ${ }^{2}$ Proteína digestível; ${ }^{3}$ Energia digestível; ${ }^{4}$ Extrato etéreo; ${ }^{5}$ Feno de Leucena; ${ }^{6}$ Feno de maniçoba; ${ }^{7}$ Feno da folha de mandioca; ${ }^{8}$ Raspas de mandioca; ${ }^{9}$ Resíduos de vitivinícola; ${ }^{10}$ Proteína digestível; ${ }^{11}$ Energia digestível.

O FL apresentou um bom valor de PD, porém uma baixa ED, a qual está relacionada à fração da PD, visto o baixo EE. O CDA do EE está relacionado à alta quantidade de fibra, fração que diminui a digestão da energia ração (MEURER \& HAYASHI, 2003). A leucena possui mimosina, um fator antinutricional cuja quantidade varia em função da cultivar(OLIVEIRA et al., 2000). Porém, a inclusão de até 20,56\% de FL em rações para a tilápia não provocou diminuição do desempenho num período de 55 dias (SEGUNDO et al., 2006).

O FM e o FFM apresentaram baixas concentrações de PD e ED. Fato relacionado ao alto nível de fibra. A fibra não é uma fonte de energia utilizada pela maioria dos peixes, ocasionando modificações na taxa de passagem do bolo alimentar (MEURER et al., 2003). A diferença em relação ao FL pode estar relacionada ao tipo de fibra, pois o tipo de fibra afeta o desempenho de alevinos de tilápia do Nilo (HAYASHI et al., 2000).

Plantas do gênero Manihot como a maniçoba e a mandioca apresentam compostos que geram ácido cianídrico. Porém o processamento adequado como a desidratação e a moagem promove a volatilização do ácido cianídrico (SOARES, 1995).

A RM e o RV são boas fontes de energia digestível, semelhantes ao amido de milho, milho extrusado e sorgo (PEZZATO et al., 2002). A RM tem uma alta concentração de amido que, aliada à boa utilização deste nutriente pela tilápia do Nilo (MEURER et al., 2004), resulta em bons níveis de ED. Já o RV tem uma concentração considerável de EE que apresenta alto CDA, um dos fatores responsáveis pela boa quantidade de ED deste ingrediente.
O feno de leucena, a raspa de mandioca e os resíduos de vitivinícola são promissores para a formulação de rações para a tilápia do Nilo. Entretanto, os fenos de maniçoba e da folha da mandioca apresentam baixos valores de digestibilidade aparente da energia e nutrientes. Porém, a utilização dos ingredientes testados na composição de rações artesanais ou comercias para a tilápia do Nilo, bem como os níveis seguros para a inclusão destes devem ser testados.

\section{COMITÊ DE ÉTICA E BIOSSEGURANÇA}

Protocolo n.29041108.

\section{REFERÊNCIAS}

BIUDES, J.F.V. et al. Digestibilidade aparente da farinha de aguapé em tilápias-do-nilo. Revista Brasileira de Zootecnia, v.38, n.11, p.2079-2085, 2009. Disponível em: <http:// w w w. s c i e lo.br/s ci e lo.ph p ? p i d = S 1516 $35982009001100001 \&$ script $=$ sci_arttext $>$. Acesso em: $25 \mathrm{fev}$. 2010. doi: 10.1590/S1516-35982009001100001.

BOSCOLO, W.R. et al. Digestibilidade aparente da energia e nutrientes de alimentos convencionais e alternativos para a tilápia do Nilo (Oreochromis niloticus, L.). Revista Brasileira de Zootecnia, v.31, n.4, p.539-545, 2002. Disponível em: <http://www.scielo.br/pdf/rbz/v31n2/10337>. Acesso em: 25 out. 2009.

HAYASHI, C. et al. Fibra bruta para alevinos de tilápia do Nilo (Oreochromis niloticus). Acta Scientiarum, v.22, n.3, p.689694, 2000. Disponível em: <http://www.scielo.br/ scielo.ph p ? p id = S 1516 - 35982003000200002 \&script=sci_arttext $>$. Acesso em: 12 nov. 2009. doi: 10.1590/ S1516-35982003000200002.

Ciência Rural, v.42, n.5, mai, 2012. 
MEURER, F. et al. Apparent energy digestibility of glycerol from biodiesel production for Nile tilapia (Oreochromis niloticus, Linnaeus 1758). Aquaculture Research, p.1-4, 2011. Disponível em: <http://onlinelibrary.wiley.com>. Acesso em: 14 out. 2011. doi: 10.1111/j.1365-2109.2011.02974.x.

MEURER, F. et al. Milheto em rações para a tilápia do Nilo (Oreochromis niloticus) durante a reversão sexual. Acta Scientiarum, v.26, p.323-327, 2004. Disponível em: <http:/ / w w w. s c i e lo.br/ s c i e lo.p h p ? p i d = S 1516 35982010000500002\&script=sci_arttext $>$. Acesso em: $19 \mathrm{abr}$. 2009. doi: 10.1590/S1516-35982010000500002.

MEURER, F. et al. Digestibilidade aparente dos nutrientes e energia de alguns alimentos protéicos para juvenis de tilápia do Nilo (Oreochromis niloticus). Revista Brasileira de Zootecnia, v.32, n. 6, p.1801-1809, 2003. Disponível em: <http:// www.scielo.br/scielo.php? script =s ci_nlinks \&ref $=000084 \&$ pid $=$ S1516-3598201000050000200012\& lng=en>. Acesso em: 26 dez. 2008.

MEURER, F.; HAYASHI, C. Polissacarídeos não amiláceos na nutrição de peixes - revisão. Arquivos de Ciências Veterinárias e Zoologia da Unipar, v.6, n.2, p.127-138, 2003. Disponível em: <http:// revistas.unipar.br/veterinaria/ article/view/805>. Acesso em: 09 jul. 2008.

OLIVEIRA, P.B. et al. Influência de fatores antinutricionais da Leucena (Leucaena leucocephala e Leucaena cunningan) e do feijão Guandu (Cajanus cajan) sobre o epitelio intestinal e o desempenho de frangos de corte. Revista Brasileira de Zootecnia, v.29, n.6, p.1759-1769, 2000. Disponível em:
< h t t p : / / w w w. revista.s bz.org.br/a r t i g o / visualizar.php?artigo=2819>. Acesso em: 09 jul. 2004

PEZZATO, L.E. et al. Digestibilidade aparente da matéria seca e da proteína e a energia digestível de alguns alimentos alternativos pela tilápia do Nilo (Oreochromis niloticus). Acta Scientiarum, v.26, n.3, p.329-337, 2004. Disponível em: <http://periodicos.uem.br/ojs/index.php/ActaSciAnimSci/ article/view/1798/1177>. Acesso em: 20 maio, 2010. doi: 10.4025/actascianimsci.v26i3.1798.

PEZZATO, L.E. et al. Digestibilidade aparente de ingredientes pela tilápia do Nilo (Oreochromis niloticus). Revista Brasileira de Zootecnia, v.31, p.1595-1604, 2002. Disponível em: <http://www.scielo.br/pdf/rbz/v31n4/ 13720.pdf>. Acesso em: 20 maio, 2010.

SANTOS, E.L. et al. Digestibilidade de subprodutos da mandioca para a tilápia do Nilo. Revista Brasileira de Ciências Agrárias, v.4, n.3, p.358-362, 2009. Disponível em: <http:/ / redalyc.uaemex.mx/s rc/inicio/ArtPdfRed.jsp ?iCve=119012585020>. Acesso em: 17 jan. 2010 .

SEGUNDO, L.F.F. et al. Substituição do farelo de soja pelo feno de Leucena na alimentação de alevinos tilápia. Revista Científica de Produção Animal, v.9, n.2, p.28-34, 2006. Disponível em: <http://www.ojs.ufpi.br/index.php/rcpa/article/ view/387>. Acesso em: 07 set. 2008

SOARES, J.G.G. Cultivo da maniçoba para produção de forragem no Semi-Árido brasileiro. Petrolina, PE: EMBRAPA-CPATSA, 1995. 4p. (EMBRAPA/CPATSA. Comunicado Técnico, 59). Disponível em: <http:// www.infoteca.cnptia.embrapa.br>. Acesso em: 16 fev. 2000. 